\title{
Heavy metal tolerance of filamentous fungi from the sediments of Visayas State University wastewater pond
}

\author{
Richie Mar M. Eliseo ${ }^{2}$ and Jayzon G. Bitacura ${ }^{1 *}$
}

The ability to tolerate high concentrations of heavy metals is one important characteristic of organisms that can be used for bioremediation. In this study, the heavy metal tolerance of filamentous fungi isolated from the VSU wastewater settlement pond was investigated. Specifically, the research was done to determine the $\mathrm{Cd}, \mathrm{Cu}, \mathrm{Fe}$ and $\mathrm{Zn}$ in the sediments of the pond, isolate and identify filamentous fungi from these sediments, identify the most tolerant isolate, and determine the minimum inhibitory concentration of heavy metals to the identified isolate. Isolation of filamentous fungi from a composite of eight sediment samples was done through serial dilution and plating using Potato Dextrose Agar (PDA). Isolates were then purified using Sabouraud Dextrose Agar (SDA). Colony and microscopic characteristics of the isolates were used to identify the isolates to genus level only. The tolerance of the isolates to $\mathrm{Cd}, \mathrm{Cu}, \mathrm{Fe}$, and $\mathrm{Zn}$ were then compared through analysis of their tolerance index based on the colony extension radius. The Minimum Inhibitory Concentrations $(\mathrm{MIC})$ of these heavy metals were obtained for the isolate with the highest tolerance index. The $\mathrm{Cd}, \mathrm{Cu}, \mathrm{Fe}$, and $\mathrm{Zn}$ contents of the composite sediment sample were $<0.0002 \mathrm{mg} \mathrm{kg}^{-1}, 0.0203 \mathrm{mg} \mathrm{kg}^{-1}, 7.419 \mathrm{mg} \mathrm{kg}^{-1}$, and $0.106 \mathrm{mg} \mathrm{kg}^{-1}$, respectively. Three filamentous fungi were successfully isolated from the sediments and were identified as Rhizopus sp., Mucor sp. and Trichoderma sp. Among these isolates, Rhizopus sp. was the most tolerant to all the heavy metals tested. Average range of MIC values of $\mathrm{Cd}, \mathrm{Cu}, \mathrm{Fe}$ and $\mathrm{Zn}$ to Rhizopus sp. were determined at $5 \mathrm{mM}<\mathrm{MIC} \leq 6.5 \mathrm{mM}, 10 \mathrm{mM}<\mathrm{MIC} \leq 15 \mathrm{mM}$, $30 \mathrm{mM}<\mathrm{MlC} \leq 35 \mathrm{mM}$, and $25 \mathrm{mM}<\mathrm{MlC} \leq 30 \mathrm{mM}$, respectively. These results showed that the Rhizopus sp. isolated is the most potential candidate in bioremediating heavy metal contaminated areas.

Keywords: Industrial effluents, heavy metal pollution, mycoremediation, tolerance index, filamentous fungi

${ }^{1}$ Department of Biological Sciences, Visayas State University, Baybay City-6521, Leyte, Philippines

2Department of Biotechnology, Visayas State University, Baybay City-6521, Leyte, Philippines

*Corresponding Author. Address: Department of Biological Sciences, Visayas State University, Baybay City-6521, Leyte, Philippines; Email: jayzon.bitacura@vsu.edu.ph 


\section{INTRODUCTION}

Heavy metal pollutants are found in various wastewaters discharged from industrial plants, business centers, and other establishments especially those that are near human settlements (Tchounwou 2014). When untreated, these effluents cause serious environmental stress and damage to the surrounding communities and ecosystems. They can cause fish kills (Slaninova et al 2014), poisoning (Rholand 2013), and various diseases (Jarup 2003). Thus, wastewater treatment is essential, and treatment through bioremediation is an excellent, safe, economical, and ecologically-friendly option.

Bioremediation is a method used to provide techniques in cleaning up pollution by enhancing the same biodegradation process that occurs in nature through the use of biological agents (Rhodes 2013). It can be achieved through either microbial remediation (using microorganisms) or phytoremediation (using plants) (Kensa 1970). Microbial remediation is the natural means of bioremediation since it involves the decomposers which occupy the bottom of the food chain, responsible for the decomposition of waste matter (Rhodes 2012, Schmitz 2008).

Among the known bioremediators are the filamentous fungi. They have hyphae, which are long, tubular structures that have rigid walls while some are reinforced by perforated cross-walls called septae (Watkinson et al 2015). Physiologically, the hyphae serve to absorb nutrients from the environment as well as translocate contaminants in the same manner they translocate nutrients from organic matter (Brand 2012, Harms et al 2011). This ability enables them to tolerate high concentrations of heavy metals in the environment and become effective for bioremediation (Bhattacharya 2011).

Heavy metal tolerance is the level at which an organism can tolerate high doses of heavy metals due to the organism's physiological and biochemical adaptation to these substances (Singh et al 2011). This characteristic is an important requirement for an organism to participate in bioremediation of toxic metals because without this, these microorganisms die when subjected to contaminated areas resulting to inefficient bioremediation (Ezzourhi et al 2009).

Heavy metal tolerant filamentous fungi are potent tools in bioremediation, for they can facilitate the removal of toxic heavy metals through translocation of contaminants in the same manner as they take in the nutrients from organic matter (Harms et al 2011). As these fungi are studied further, they may help prevent the loss of our natural resources such as food in the case of fish kills (Slaninova et al 2014), cleaning our environment and making a better environment for future generations.

The main campus of Visayas State University (VSU) is composed of upper and lower campuses. In the lower campus, the wastewater treatment is held in a wastewater pond. The pond is the reservoir of all waste effluents from students' dormitories, laboratories, faculty and staff housing units, academic buildings, hostel, hospital, and other structures inside the university. This pond treats the pollutants by sedimentation process wherein solid pollutants settle to the bottom.

Thus, this study aimed to determine the $\mathrm{Cd}, \mathrm{Cu}, \mathrm{Zn}$, and Fe concentrations in the sediments of the VSU wastewater pond, isolate and identify filamentous fungi from these sediments, select the most tolerant isolate, and determine the minimum inhibitory concentration of these heavy metals to the isolate. 


\section{MATERIALS AND METHODS}

\section{Sampling and Preparation}

All materials including the culture media were sterilized at $121^{\circ} \mathrm{C}, 15 \mathrm{psi}$ for $15 \mathrm{~min}$. Sediment samples were collected from eight (8) different points in the sampling site (Figure 1) using a grab sampler. A 500 gram-composite sample was placed in a sterile bottle (Ezzouhri et al 2009), and the remaining samples were airdried and sent to the F.A.S.T. Laboratory in Mandaue City, Cebu, Philippines for analysis of $\mathrm{Cd}, \mathrm{Cu}, \mathrm{Fe}$, and $\mathrm{Zn}$. Data for the heavy metal content of the VSU wastewater pond in 2012 and 2016 were taken from the unpublished research of Valenzona and Dacera et al, respectively.

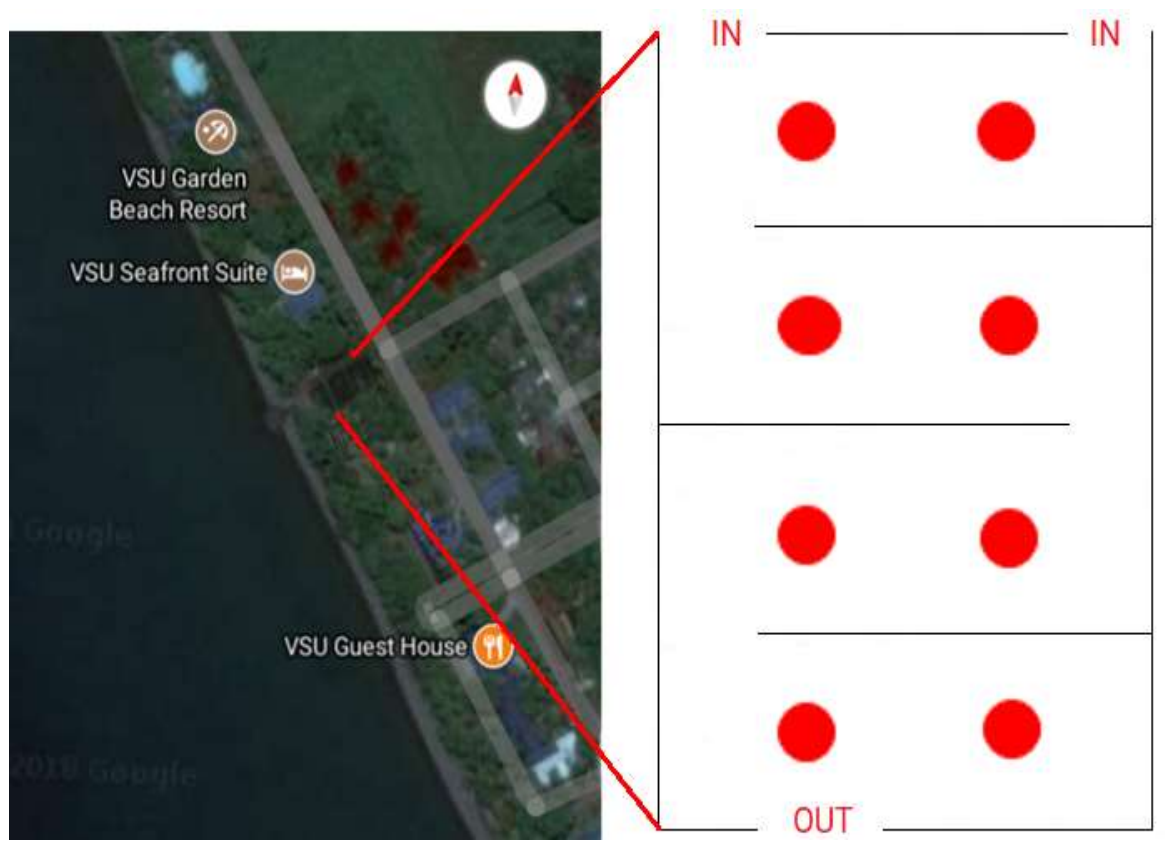

Figure 1. Sampling points within Visayas State University wastewater pond. Source: Google Maps 2019

\section{Isolation of Filamentous Fungi}

One (1) g of the natural composite samples was suspended in a sterile $500 \mathrm{~mL}$ beaker filled with $100 \mathrm{~mL}$ distilled water and then covered with parafilm. The mixture was agitated for $20 \mathrm{~min}$ at room temperature. Subsequently, the mixture was diluted in sterile beakers at 10,100, 1000, and 10000 fold of serial dilution (Ezzouhri et al 2009).

Thirty-nine (39) g of Potato Dextrose Agar (PDA) were dissolved in an Erlenmeyer flask containing $1 \mathrm{~L}$ distilled water and covered with an autoclavable plastic. The solution was then sterilized at $121^{\circ} \mathrm{C}, 15 \mathrm{psi}$ for $15 \mathrm{~min}$ prior to isolation of the heavy metal- tolerant fungi. Three replicates of $100 \mu \mathrm{L}$ aliquots from the 
different dilutions of the sample sediments were plated onto the sterile plates containing solidified PDA, using lawn method. The inoculated plates were incubated for three days at $25^{\circ} \mathrm{C}$. The distinct colonies that grew on the PDA plates were picked by slicing-off the agar from the plate and transferring them onto fresh SDA medium. They were then incubated for three days at $25^{\circ} \mathrm{C}$ (Ezzouhri et al 2009). Subsequent transfers to fresh Sabouraud Dextrose Agar (SDA) plates were made until pure cultures of the isolates were attained.

\section{Identification of the Filamentous Fungal Isolates}

Colonial and cellular characteristics of the filamentous fungal isolates were evaluated to identify them down to their lowest possible taxon. These characteristics include texture and color as viewed under the stereoscope.

For cellular characterization, the fungal colony of each isolate was inoculated on a sterile glass slide with PDA and placed inside a petri plate with sterile wet cotton to provide moisture. After at least three days of incubation, it was stained with lactophenol cotton blue and topped with coverslip. When the fungal colonies were already sufficiently stained, they were examined under a compound light microscope (True Vision Microscope, USA) to assess their cellular characteristics. Photomicrographs were taken using Amscope 5MP camera directly mounted on the microscope to aid in identification.

\section{Screening and Selection of Isolates with High Heavy Metal Tolerance}

The filamentous fungal isolates were screened for their tolerance to cadmium $(\mathrm{Cd})$, copper $(\mathrm{Cu})$, iron (Fe), and zinc $(\mathrm{Zn})$ based on the method of Ezzouhri et al (2009). Each of the PDA plates was supplemented with $1 \mathrm{mM}$ of a specific metal salt. Aseptically, disks of mycelium were inoculated onto the PDA plates and incubated at $25^{\circ} \mathrm{C}$. After 7 days incubation, fungal growth was determined by measuring the radius $(\mathrm{mm})$ of the colony extension of the fungal mycelia in the agar. Tolerance index was then calculated as the ratio of the extension radius of the treated colony (with heavy metal) to the untreated colony (without heavy metal). The tolerance indices of the isolates were analyzed statistically identify the isolate showing the highest tolerance to all the heavy metals tested.

\section{Minimum Inhibitory Concentration (MIC) Testing}

Testing for the MIC was carried out only on the most tolerant filamentous fungal isolate. Each of the fresh SDA media was first supplemented with a specific heavy metal based on the concentrations used by Ezzouhri et al (2009), 0 to 35mM or higher until the concentration that totally inhibited the growth of the fungus was reached. The media containing different concentrations of the heavy metal salts were inoculated with $6 \mathrm{~mm}$ agar disks from the young fungal colonies. The inoculated plates, in triplicate, were incubated for 7 days at $25^{\circ} \mathrm{C}$. The minimum concentration of the heavy metal that inhibited visible growth of the isolate was regarded as the MIC (Ezzouhri et al 2009). 


\section{Experimental Design and Statistical Analysis}

The experiment was laid in a completely randomized design (CRD). Analysis of variance (ANOVA) was performed followed by Tukey's Honest Significant Difference (HSD) test for multiple comparison of means at alpha $=0.01 \%$. All the analyse were carried out using IBM SPSS Statistics 22 software.

\section{RESULTS AND DISCUSSION}

\section{Heavy Metal Content of the Sediments from the VSU Wastewater Pond}

The VSU wastewater pond is the wastewater treatment facility of the university where effluents from faculty and staff housing, academic buildings, and laboratories are treated by sedimentation process. The heavy metal contents of the pond in 2012, 2016, and 2019 are shown in Table 1. The concentration of $\mathrm{Cd}$ and $\mathrm{Cu}$ from 2012 (Valenzona 2012) to 2016 (Dacera et al 2016) were from $0.074 \mathrm{mg} \mathrm{kg}^{-1}$ to $0.83 \mathrm{mg} \mathrm{kg}^{-1}, 0.0324 \mathrm{mg} \mathrm{kg}^{-1}$ to $78.3 \mathrm{mg} \mathrm{kg}^{-1}$ and 0.9703 to $25 \mathrm{mg} \mathrm{kg}^{-1}$, respectively. This probably means that there was a continuous heavy metal discharge into the pond from 2012 to 2016, which resulted to the increase in the heavy metal concentrations in the pond. However, in 2019 , the concentration of heavy metals decreased. There could have been a decrease in the heavy metal input to the pond or probably there was bioremediation carried out by the microbial population and plant species found in the area, or a combination of both. In 2012 and 2016, the studies of Valenzona and Dacera, respectively, showed that the area was devoid of vegetation, but in 2019, Eliseo reported that plants were already found growing around the area.

Table 1. Heavy metal contents of the VSU wastewater pond sediments in 2012, 2016, and 2019

\begin{tabular}{lccc}
\hline \multirow{2}{*}{ Heavy Metal } & \multicolumn{3}{c}{ Concentration $(\mathrm{mg} \mathrm{per} \mathrm{kg})$} \\
\cline { 2 - 3 } & Valenzona 2012 & Dacera et al 2016 & Eliseo 2019 \\
\hline Cadmium & 0.0747 & Less than 0.83 & Less than 0.0002 \\
Copper & 0.0324 & 78.3 & 0.0203 \\
Lead & 0.9703 & 25 & 0.00315 \\
Iron & No data & No data & 7.419 \\
Zinc & No data & No data & 0.106 \\
\hline
\end{tabular}

\section{Characteristics of the Filamentous Fungal Isolates}

Figure 2 shows the colony and cellular characteristics of the three filamentous fungi isolated in this study. The fungi isolated from the sediments designated as Isolate 1, Isolate 2 and Isolate 3 belong to the genera Rhizopus, Mucor and Trichoderma, respectively. Isolate 1 has black-colored colonies producing circular sporangia enclosing the spores, and it had non-septate stolons (Figure 2 first row). These morphological characteristics describe the genus Rhizopus of Phylum Oomycota. The genus Aspergillus of Phylum Eumycota may also have some of these characteristics, except that they produce septate mycelia. 


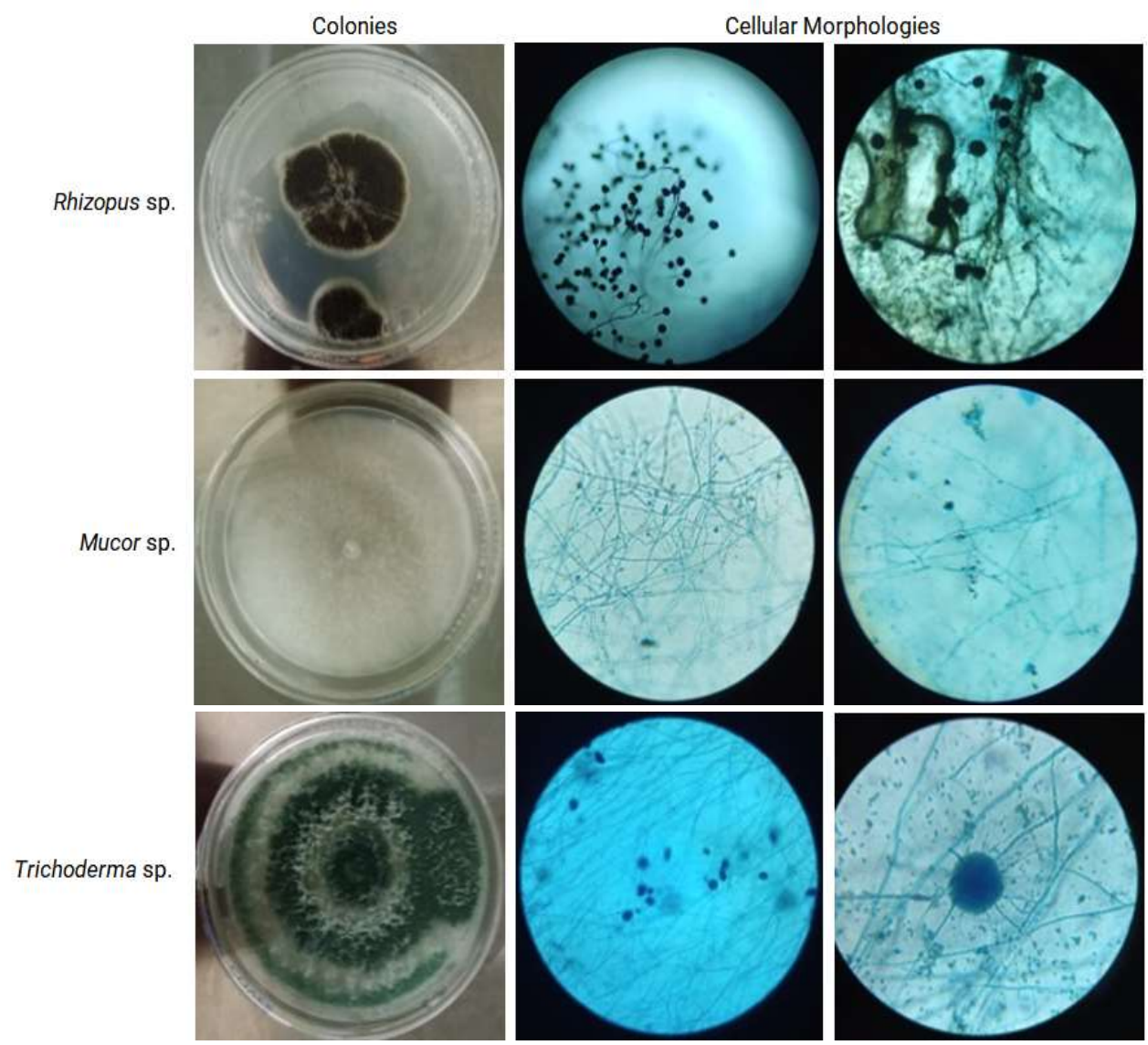

Figure 2. Colony and cellular characteristics of the filamentous fungal isolates grown for 7 days on SDA. Photomicrographs were taken at 100X (middle column) and 400X (right column).

The colonies of Isolate 2 were white-colored, cottony-like at the early stage, and had pin-like sporangia and sporangiophores. They had no distinct stolon structure, instead the sporangiophore produced branches that were aseptate. These are characteristics of the genus Mucor under the Phylum Oomycota (Figure 2 second row). On the other hand, isolate 3 colonies were deep green in color, cottony-like at early stage, and had branched conidiophores. There were no stolons and septae, and the spores were not enclosed in a sporangium, which characterize the genus Trichoderma (Figure 2 third row).

In a study done by Manguilimotan and Bitacura (2018), eight Cd-tolerant filamentous fungi were isolated from the coastal waters and sediments near the effluent sites of the industrial plants in Barangay Ibo, Lapu-Lapu City, Cebu. In terms of $\mathrm{Cd}$ biosorption activity, only three isolates were found to be most efficient. Two of them belonged to genus Aspergillus and one to genus Penicillium. Neither of those two genera was isolated in the present study. Furthermore, Rhizopus and Trichoderma were also among the filamentous fungi isolated by Zafar et al (2007) from agricultural soils with long term input of wastewater from their municipality and industry. 


\section{Heavy Metal Tolerance of the Fungal Isolates}

The fungal isolates were screened for their tolerance to $1 \mathrm{mM}$ each of $\mathrm{Cd}, \mathrm{Cu}, \mathrm{Fe}$ and $\mathrm{Zn}$ (Figure 3). Figure 4 shows that $\mathrm{Cu}$ was the most tolerated heavy metal by Rhizopus sp. followed by Fe, Zn, and Cd. Mucor sp., was most tolerant to Fe and Zn followed by $\mathrm{Cu}$ then $\mathrm{Cd}$. Trichoderma sp. was most tolerant to Fe then $\mathrm{Zn}$ and $\mathrm{Cu}$, but least tolerant to $\mathrm{Cd}$. Figure 5 shows that Rhizopus sp. exhibited the highest tolerance index to all the heavy metals tested compared to that of Trichoderma sp. and Mucorsp.

In a similar study conducted by Zafar (2007), Rhizopus and Trichoderma, isolated from heavy metal contaminated agricultural soils, were found to be tolerant to $\mathrm{Cd}, \mathrm{Ni}, \mathrm{Cr}, \mathrm{Cu}$, and $\mathrm{Co}$. Meanwhile, Oladipo et al (2018) found Rhizopus and Trichoderma, isolated from gold and gemstone mine site soils, as tolerant to $\mathrm{Cu}, \mathrm{Pb}$, and Fe.

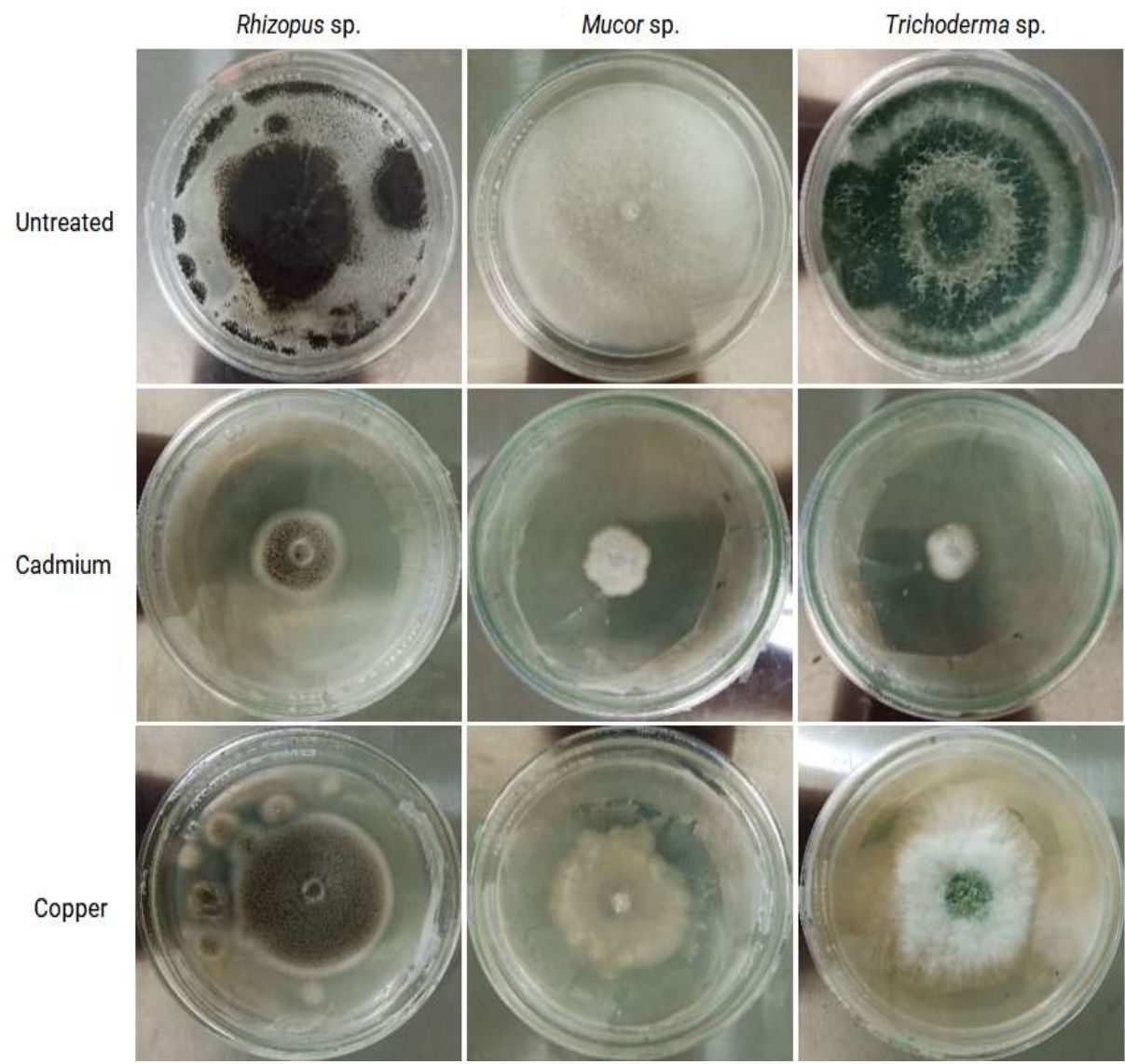

Figure 3. Growth of the fungal isolates after 7 days on PDA with and without $1 \mathrm{mM}$ heavy metal treatment 
Eliseo and Bitacura

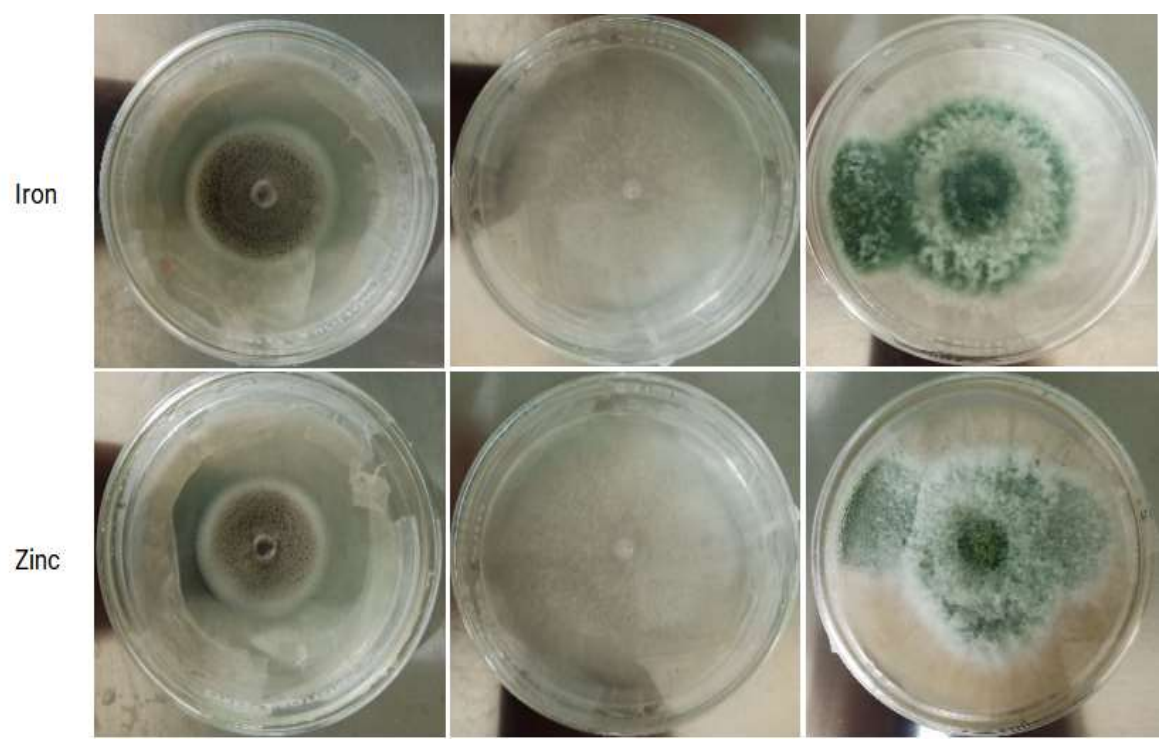

Figure 3 continued

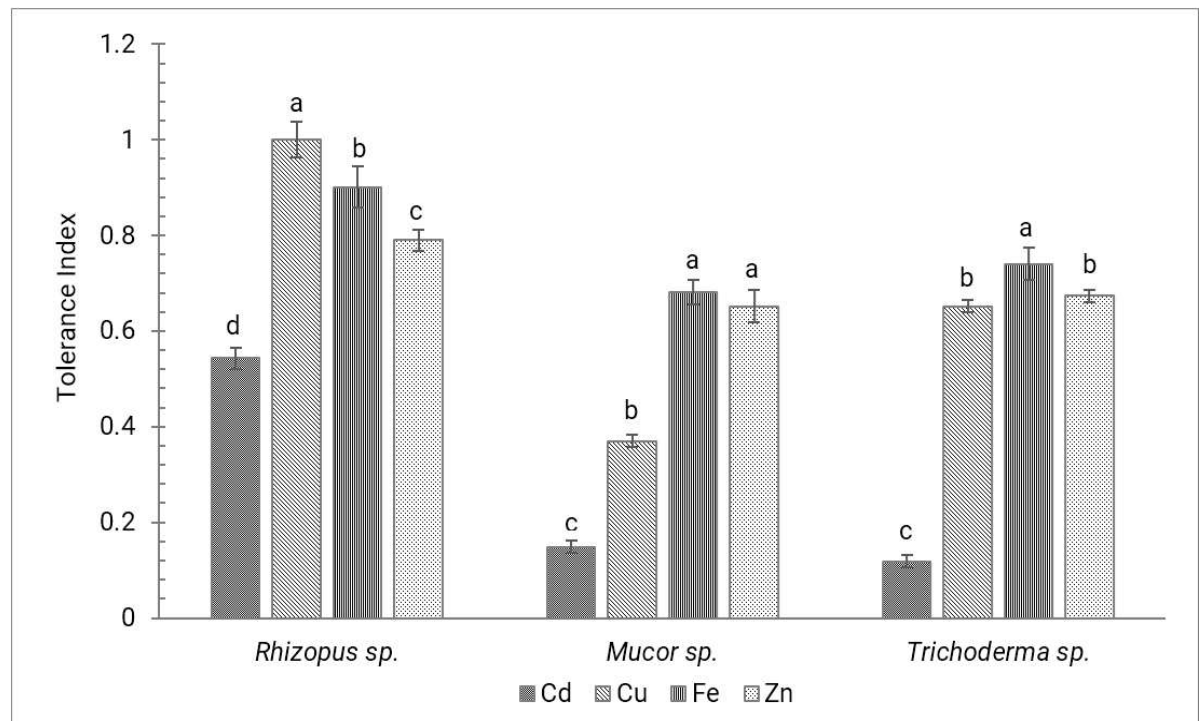

Figure 4. Tolerance indices of fungal isolates (Mean $\pm S D$ ) to $1 \mathrm{mM}$ of heavy metal salts. Levels having the same letter designations are not significantly different at $p<0.01$ 


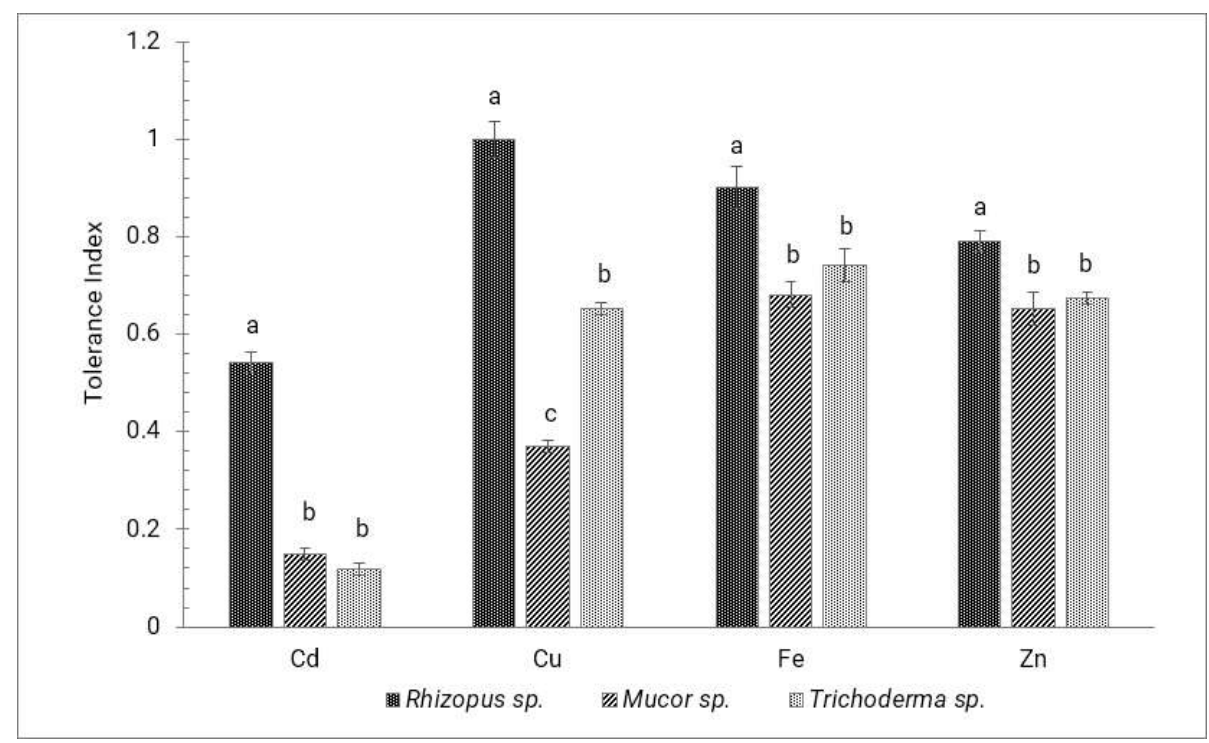

Figure 5. Comparative tolerance indices (Mean \pm SD) of the fungal isolates to $1 \mathrm{mM}$ heavy metal salts. Levels having the same letter designations are not significantly different at $p<0.01$

\section{Minimum Inhibitory Concentration of the Heavy Metals Against Rhizopus sp.}

The minimum inhibitory concentration of the four heavy metals against the fungal isolate is summarized in Table 2 and Figure 6. Rhizopus sp. was shown to tolerate Cu concentrations of 10 to $15 \mathrm{mM}$ only. Cadmium, on the other hand, was the most growth-inhibiting to the fungal isolate. Maximum $\mathrm{Cd}$ concentration in which the fungus was able to grow was between 5 to $6.5 \mathrm{mM}$. The highest heavy metal concentration that Rhizopus sp. can grow is in Fe with a minimum inhibitory concentration of $30 \mathrm{mM}<\mathrm{MIC} \leq 35 \mathrm{Mm}$, followed by $\mathrm{Zn}$ with $25 \mathrm{mM}<\mathrm{MIC} \leq 30 \mathrm{mM}$.

Table 2. Range of average Minimum Inhibitory Concentration (MIC) of the heavy metals tested with Rhizopus sp.

\begin{tabular}{ccccc}
\hline \multirow{2}{*}{ Fungal Isolate } & \multicolumn{4}{c}{ Minimum Inhibitory } \\
\cline { 2 - 5 } & $\mathrm{Cd}^{2+}$ & $\mathrm{Cu}^{2+}$ & $\mathrm{Fe}^{2+}$ & $\mathrm{Zn}^{2+}$ \\
\hline Rhizopus sp. & $5<\mathrm{MIC} \leq 6.5$ & $10<\mathrm{MIC} \leq 15$ & $30<\mathrm{MIC} \leq 35$ & $25<\mathrm{MIC} \leq 30$ \\
\hline
\end{tabular}

The growth of the fungal isolates observed in this study was similar to the report of Ezzouhri et al (2009) wherein the growth pattern first exhibited a lag phase, then retardation phase, after which no additional enhancement in growth was observed. In the present study, there was a longer lag phase (adjustment period) in the heavy metal treatments compared to the control. As the concentration of the heavy metal was increased, the colony extension decreased (Figure 6). This may mean that the fungus developed tolerance or adaptation during incubation as suggested by Ezzouhri et al (2009). Furthermore, increasing the heavy metal concentration appeared to slow down the growth of the mycelia. 
The presence of a longer lag phase at higher heavy metal concentrations suggests that tolerance development or adaptation may have occurred during incubation. According to Gadd (1993), a reduction in the growth of a fungus is a natural response to toxicants but an increase in the length of the lag phase is not always present. Additionally, dependency on lag time is not always present according to the study of Darlington and Rauser (1988) wherein Penicillium involutus did experience an extended lag phase. Lengthening of lag phase is not always present probably because the fungus is tolerant enough to higher concentrations of the heavy metals.

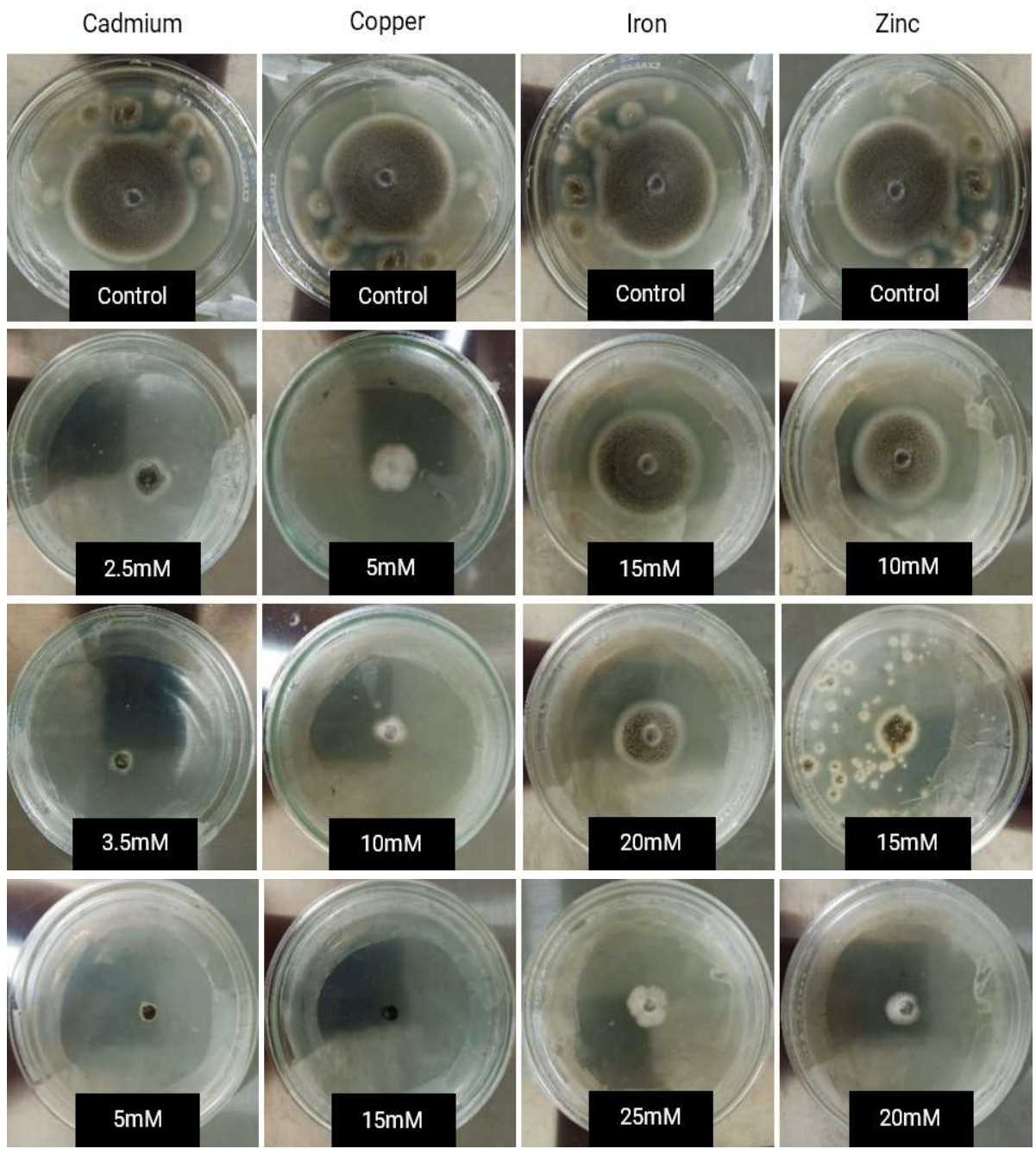

Figure 6. Growth of Rhizopus sp. after 7 days on PDA with different concentrations of Cd, Cu, Fe and Zn salts 


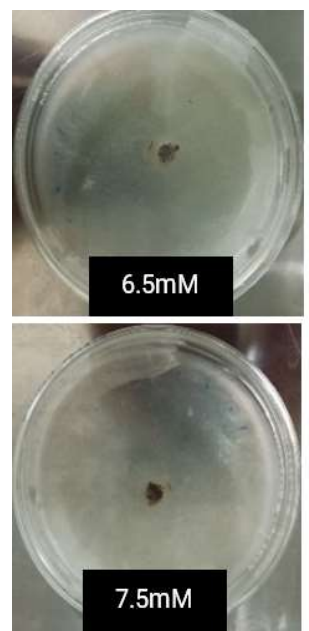

$7.5 \mathrm{mM}$
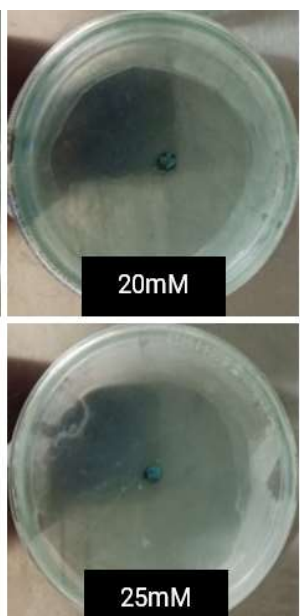

$25 \mathrm{mM}$
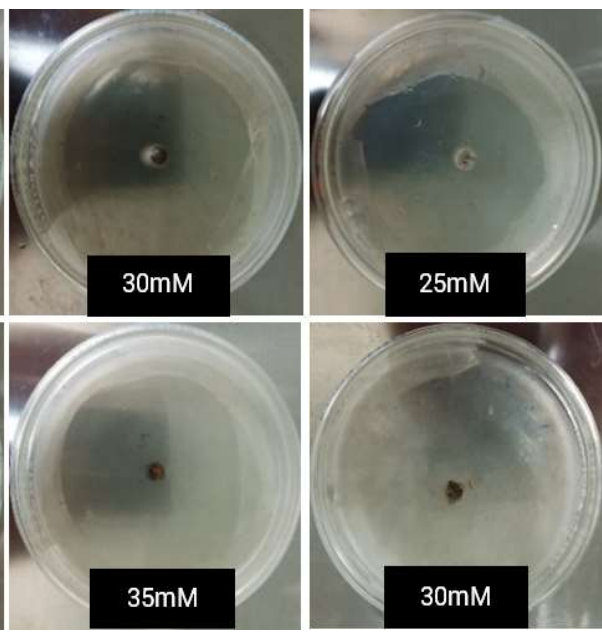

$30 \mathrm{mM}$

Figure 6 continued

Among the fungal isolates, Rhizopus sp was the most tolerant to $\mathrm{Zn}$ and $\mathrm{Fe}$ (Figure 4). Its colony color became lighter and the mycelia grew thinner compared to the control. These were manifestations of the stress caused by the heavy metals. $\mathrm{Cu}$ is a co-factor in many enzymatic processes and is the $3^{\text {rd }}$ most abundant transition heavy metal found in living organisms (Brandolini et al 2002). Rhizopus sp. showed high tolerance to $1 \mathrm{mM}$ of $\mathrm{Cu}$, but when the concentration was increased its growth was slow. It was the third heavy metal that the fungus could tolerate the most. The fungus grew smaller compared to those that grew on Fe and $\mathrm{Zn}$. There was blue coloration of the mycelium inoculated on the $\mathrm{Cu}$-treated medium, which may indicate that $\mathrm{Cu}$ ions were bound to the fungal cell walls. Anand et al (2006) and Ezzouhri et al (2009) also reported similar observations. The MIC of Rhizopus sp. to $\mathrm{Cu}$ was $10<\mathrm{MIC} \leq 15 \mathrm{mM}$ which was lower than that of Aspergillus sp. which was 15-20mM as reported by Ezzourhi et al (2009).

Cadmium is a by-product of $\mathrm{Zn}$ production and is a well-known carcinogen and teratogen (New Jersey-DOH 2007). In Figure 3, the growth of the fungus in Cdtreated medium was very low compared to those cultured with other metals, making it the most toxic heavy metal compared to $\mathrm{Cu}, \mathrm{Fe}$, and $\mathrm{Zn}$. In a similar study by Ahmad et al (2005), Rhizopus sp. isolated from wastewater-treated soil had an MIC of $1 \mu \mathrm{g} \mathrm{mL}^{-1}$. Additionally, it was found to be more biosorptive than Aspergillus $\mathrm{sp}$. The low MIC may have been due to the high toxicity of the heavy metal.

Tolerance of filamentous fungus may also be directly related to the concentration of the heavy metals in the sediments (Ahmad et al 2005). In the sediment samples collected from the settling pond, the concentrations of Fe and $\mathrm{Zn}$ were much higher than those of $\mathrm{Cu}$ and $\mathrm{Cd}$. This heavy metal tolerance is very important because when there is no tolerance to heavy metals, they grow slow and eventually die. It would be cost ineffective if they are used in contaminated areas for bioremediation.

In this study, the MIC of Rhizopus sp. to Cd appeared to indicate that its tolerance to this metal was not fully developed which may be due to the low concentration of $\mathrm{Cd}$ in the settling pond (Table 1). For $\mathrm{Cu}$, its concentration in the settling pond was higher, which could have induced the fungus to develop more 
tolerance to the metal. Rhizopus sp. was most tolerant to $\mathrm{Cu}$ at $1 \mathrm{mM}$ or $159.609 \mathrm{mg}$ $\mathrm{kg}^{-1}$ but tolerance decreased at much higher concentrations of $\mathrm{Cu}$. In contrast, high tolerance of Rhizopus sp. to Fe and Zn was still observed even at much higher concentrations. This means that the fungus may have developed higher tolerance to the heavy metals in response to the high metal concentrations in the pond sediments (Table 1). This may be an indication that Rhizopus sp. has a high bioremediating potential in heavy metal polluted waters.

In a study done by Pal et al (2010), a heavy metal tolerant strain of Rhizopus arrhizus accumulated lead in the cell walls and that cellular metabolism could be involved in the bioaccumulation of the heavy metal by the fungus. Moreover, Tsekova and Galabova (2003) reported that the acid phosphatase production in Rhizopus delemar in and out of the cells after exposure to $\mathrm{Cu}$ ions is necessary for its heavy metal resistance and bioaccumulation.

\section{CONCLUSION}

Three filamentous fungi were successfully isolated from the sediments and were identified as Rhizopus sp., Mucor sp. and Trichoderma sp. The most tolerant isolate to all four heavy metals tested was Rhizopus sp. It tolerated Cu the most, and Cd the least. The MIC values of $\mathrm{Cd}, \mathrm{Cu}, \mathrm{Fe}$, and $\mathrm{Zn}$ to Rhizopus sp. were at $5 \mathrm{mM}<\mathrm{MIC} \leq 6.5 \mathrm{mM}$, $10 \mathrm{mM}<\mathrm{MIC} \leq 15 \mathrm{mM}, 30 \mathrm{mM}<\mathrm{MIC} \leq 35 \mathrm{mM}$ and $25 \mathrm{mM}<\mathrm{MIC} \leq 30 \mathrm{mM}$, respectively. These results indicate that Rhizopus $\mathrm{sp}$. is a potential candidate species for bioremediation of $\mathrm{Cu}, \mathrm{Fe}$, and $\mathrm{Zn}$-contaminated waters. It is recommended that further studies on its heavy metal biosorption, bioaccumulation capacity, and other mechanisms of bioremediation be conducted.

\section{ACKNOWLEDGMENT}

The authors would like to thank Dr. Ma. Theresa P. Loreto, Dr. Nestor L. Pido, and Ms. Caressa Marielle D. Poliquit for their invaluable critique of the manuscript. This study is partly supported by a research funding from the study "Assessment and monitoring of fungi in VSU water resources" which is part of the project "Biological and Physico-chemical Characteristics and Utilization of VSU Water Resources" funded by the Visayas State University.

\section{REFERENCES}

Ahmad I, Zafarn S \& Ahmad F. 2005. Heavy metal biosorption potential of Aspergillus and Rhizopus sp. Isolated from wastewater treated soil. Journal of Applied Sciences and Environmental Management 9(1):123-126

Anand P, Isar J, Saran S \& Saxena R. 2006. Bioaccumulation of copper by Trichoderma viride. Bioresource Technology 97(8):1018-1025

Balsalobre L, De Siloniz MI, Valderrama MJ, Benito T, Larrea MT \& Peinado JM. 2003. Occurrence of yeasts in municipal wastes and their behavior in presence of cadmium, copper and zinc. Journal of Basic Microbiology 43(3):185-193

Bhattacharya SE. 2011. Mycoremediation of Congo red dye of filamentous fungi. Brazilian Journal of Microbiology 42(4):1526-1536 
Brand A. 2012. Hyphal growth on human fungal pathogens and its role in virulence. International Journal of Microbiology 2012:517-529

Brandolini V, Tedeschi P, Capece A, Maietti A, Mazzotta D, Salzano G, Paparella A \& Romano P. 2002. Saccharomyces cerevisiae wine strains differing in copper resistance exhibiting capability to reduce copper content in wine. World Journal of Microbiology and Biotechnology 18(6):499-503

Canadian Council of Ministers of the Environment (CCME). 1992. Canadian water quality guidelines, CCME, Inland Water Directorate, Ottawa, Ontario. In Drotse R (ed) Theory and Practice of Water and Wastewater Treatment (pp790). John Wiley and Sons, Inc

Dacera DP, Cortes DS, David FC, Miraflor KS, Plimaco PT \& Bitacura JG. 2016. Filamentous fungi from coastal sediments as novel indicators of long-term heavy metal contamination (Unpublished research). VSU Laboratory High School

Darlington AB and Rauser WE. 1998. Cadmium alters the growth of the mycorrhizal fungus Paxillus involutus: a new growth model accounts for changes in branching. Canadian Journal of Botany 66(2):225-229

Ezzouhri L. 2009. Heavy metal tolerance of filamentous fungi Isolated from polluted sites in Tangier, Morocco. African Journal of Microbiology Research 3(2):35-48

Gadd G. 1993. Interactions of fungi with toxic metals. New Phytologist 124:25-60

Harms H. 2011. Untapped potential exploiting fungi in bioremediation of hazardous chemicals. Nature Reviews Microbiology 9:177-192

Jarup L. 2003. Hazards of heavy metal contamination. British Medical Bulletin 68(1):167-182

Kensa MV. 2011. Bioremediation - an overview. Journal of Industrial Pollution Control 27(2):161-168

Manguilimotan LC and Bitacura JG. 2018. Biosorption of cadmium by filamentous fungi isolated from coastal water and sediments. Journal of Toxicology 2018:16

New Jersey Department of Health. 1999. Right to know hazardous substance fact sheet. https://web.doh.state.nj.us/rtkhsfs/indexfs.aspx

Oladipo OG, Awotoye O0, Olayinka A, Bezuidenhout CC \& Maboeta MS. 2018. Heavy metal tolerance traits of filamentous fungi isolated from gold and gemstone mining sites. Brazilian Journal in Microbiology 49(1):29-37

Pal TK, Bhattacharyya S \& Basumajumdar A. 2010. Cellular distribution of bioaccumulated toxic heavy metals in Aspergillus niger and Rhizopus arrhizus. International Journal of Pharma and Bio Sciences 1(2):1-6

Rhodes C. 2013. Application of bioremediation and phytoremediation. Science Progress 96(4):417-427

Rholand L. 2013. Merritt's neurology. Lippincoott Williams \& Wilkins (LWW)

Singh R. 2011. Heavy metals and living systems: an overview. Indian Journal of Pharmacology 43(3):246-253

Slaninova A. 2014. Fish kill caused by aluminum and iron contamination in natural pond used for fish rearing: a case report. Veterinární Medicína 59(11):573-581

Tchounwou PB, Yedjou CG, Patlolla AK, Sutton DJ. 2012. Heavy metal toxicity and the environment. In Luch A (ed) Molecular, Clinical and Environmental Toxicology. Experientia Supplementum 101:133-164. Springer, Basel

Tsekova K and Galabova D. 2003. Phosphatase production and activity in copper (II) accumulating Rhizopus delemar. Enzyme and Microbial Technology 
33(7):926-931

Valenzona H. 2012. Cadmium, lead and copper analysis of water from the Visayas State University wasterwater lagoon using flame atomic absorption Spectrophotometry (Undergraduate thesis). Visayas State University, Philippines

Watkinson S, Boddy L \& Money N. 2015. The fungi (3rd edn). Academic Press

Zafar S. 2007. Metal toleramce and biosorption potential of filamentous fungi isolated from metal contaminated agriculture soil. Bioresource Technology 98(13):2557-2561 